\title{
Developing Strategy for a Successful Antioxidant, Anticancer Activity via an Improved Method Prepared to Porous Silicon Nanoparticles
}

\author{
${ }^{1}$ Kareem H. Jawad, ${ }^{2}$ Butheina A. Hasson* \\ ${ }^{1}$ Department of Medical Engineering, University of Technology - Iraq \\ ${ }^{2}$ Division of Biotechnology, Department of Applied Sciences, University of Technology - Iraq
}

Article information

Article history:

Received: June, 21, 2021

Accepted: July, 27, 2021

Available online: December, 04, 2021

Keywords:

PSNPs,

Antioxidant,

Anticancer-activity

*Corresponding Author:

Butheina A. Hasson

100235@uotechnology.edu.iq

\begin{abstract}
Porous silicon nanoparticles, or PSNPs, are one of the most common NPS with distinct characteristics. PSNPs were created using an enhanced approach known as the electrochemical etching process. The nanoparticles were treated with a post-laser to obtain the nanoparticles, which were subsequently analyzed using (SEM), (UV-Vis), and (XRD). The size refers to porous silicon with a nanostructure. Because of the differences in interaction between the HF electrolyzed and silicon and crystal structure, PS (100) offers better NP properties than directional silicon (111). PSNPs' antioxidant activity was measured using the DPPH test, while cytotoxicity was measured using the MTT assay on Hella cells. PSNPs have an inhibitory impact on cancer cell growth and antioxidants, according to the findings. PSNPs did not have any toxicological effects on the skin, lungs, or spleen after injection.
\end{abstract}

DOI: 10.53293/jasn.2021.3890.1054, C2021, Department of Applied Sciences, University of Technology

This is an open access article under the CC BY 4.0 License.

\section{Introduction}

PS is a porous semiconductor with a high reactivity because of its huge surface area and surface chemistry. On its surface, it is possible to create a precise chemical composition or molecule adsorption [1]. PS is also a good biomaterial since it is biodegradable and biocompatible [2]. These PS bio-characterizations are large-scale productions that rely on their oxidation susceptibility. Body fluids dissolve the silicon oxide [3]. Later, it is excreted in the urine as silicic acid, which is non-toxic [4]. PS has also been mixed with other materials, injected into its pores, or coated on its surface to create composites. [5] That can broaden or deepen its range of uses and personality, including the bio [3,6]. PS research in medical and non-medical applications is still increasing in this regard since it is a viable biomaterial for commercial use. Silicon, as well as the substrate on which it is manufactured, is a low-cost commodity that is suitable for use in the high-tech electronics sector. Drug delivery and cell scaffolds are two of the most common uses of PS as a biomaterial. PSi-based devices geared toward these applications are becoming more common [7, 8]. PSi became a potential material for optoelectronic applications as a result of these properties, and papers devoted to PSi increased dramatically in the 1990s [9]. Optoelectronics [10], Bragg reflectors [11], solar cells [12], and photodetectors [13] are among the most PSi applications in lightemitting devices (LEDs) and optical waveguides [14]. 
The goals of this work are to synthesize colloidal silicon NPS utilizing electrochemical etching and laser in liquid techniques, as well as to investigate the influence of silicon NPs on antioxidant and anticancer activities in vitro and in vivo models.

\section{Experimental Procedure}

\subsection{PSNPs production}

Porous silicon (PS) samples were created by electrochemical etching silicon wafers (100) doped with orientated boron and having a thickness of (55050) nm (Diameter $7.6 \mathrm{~cm}$ ). (Resistivity 1.5-4.cm) and (Resistivity 1.5-4.cm) (central circular of $\left.5.5 \mathrm{~cm}^{2}\right)$. He employed a 1:1 (v/v) electrolyte of hydrofluoric acid (24\%) and ethanol $(99.9$ percent). After that, the NPs were dissolved in deionized water and placed in an ultrasound instrument for four hours. The NPS was then created using a filter that allowed NPs with a size of up to $0.22 \mathrm{~m}$ to pass through [15]. Finally, NPs were generated using a post-laser with a wavelength of $1064 \mathrm{~nm}$ and laser intensity of $350 \mathrm{~mJ}$.

\subsection{Characterization PSNPs}

\subsubsection{UV-Vis, SEM, XRD}

PSNPs were optically analysed using UV-Vis within the spectral range of 200-900 $\mathrm{nm}$. SEM was utilized to generate pictures from the surface of a sample, and XRD analysis was performed to validate the structure. The PSNPs chart by UV-Vis, XRD, and SEM were done in the service centre University of Baghdad.

\subsection{Antioxidant Activity: DPPH Assay}

Antioxidant activity of PSNPs wear calculated using DPPH assay with minor adjustments according to [16,17]. Extract was applied to investigate the scavenging activity. Every sample were mix up with DPPH solution and then completes the quantity to one $\mathrm{mL}$ using ethanol. Absorbance was calculated at $517 \mathrm{~nm}$. Scavenging activity computed corresponding to the equation formula:

$$
\text { Antioxidant activity } \%=\frac{\text { OD }^{A}-\text { OD }^{B}}{\text { OD }^{\text {B }}} * 100
$$

$\mathrm{OD}=$ optical density, $\mathrm{A}=$ control, $\mathrm{B}=$ sample

\subsection{Detection of the Toxicity}

\subsubsection{Maintenance of Cell Cultures}

Cervical cancercell line of Hella cell line, from the unit of Cell Bank of Iraq biotech, saved RPMI-1640 Completed by $(100)$ units $/ \mathrm{mL}$ of both penicillin, streptomycin antibiotic's and $(10 \%)$ from fetal bovine. Cells were passaged by Trypsin-EDT Are-seeded at (50\%) confluence for 14 days at $37^{\circ} \mathrm{C}[18]$.

\subsubsection{Cytotoxicity Assays}

The MTT test was used to assess cytotoxic effects. Cell lines were cultured in a well of (1640 cells). The monolayer was reached after $24 \mathrm{~h}$, and the cells were treated with the tested drug. After $72 \mathrm{~h}$, the viability of the cells was determined by extracting the medium and incubating the cells for $1.5 \mathrm{~h}$. at $37^{\circ} \mathrm{C}$ with $28 \mu \mathrm{L}$ of $2 \mathrm{mg} / \mathrm{mL} \mathrm{MTT}$ solution. After that the MTT stain was eliminated and solubilized the rock crystal that staying in the wells by the add-on $(130 \mu \mathrm{l})$ of DMSO followed by keep at $37^{\circ} \mathrm{C}$ for $15 \mathrm{~min}$ [18]. The absorbency was determined on a micro plate reader at $492 \mathrm{~nm}$. The percentage was determination as the following calculation:

$$
\text { Inhibition rate }==O D^{\mathrm{A}}-=\mathrm{OD}^{\mathrm{B}} / \mathrm{OD}^{\mathrm{A}} * 100
$$


$\mathrm{A}=$ Optical density of control, $\mathrm{B}=$ Optical density of test.

\subsection{In-Vivo Model Experiment}

The Biotechnology Research Centre provided albino male mice (Al-Nahrain University). They were 8-10 weeks old when the trials began, and their average weight was 35-45 grams. They were divided into five groups, each of which had three mice that were housed in their own plastic cage (details of these groups are given in the section of experimental design). The animals were kept at room temperature and given access to unlimited food and water. In this experiment, $1 \mathrm{mg} / \mathrm{kg}$ was the dose of PSNPs, and assess the toxicity effects of this dose, the mice were distributed into five groups, and each group contains three animals (total: 15 mice): [19,20].

Group I: Mice were administrated with physiological saline (Negative controls.)

Group II: (Injection PS NPs), Killing after a week.

Group III: (Injection PSNPs), Killing after two weeks.

Group IV: (Injection PSNPs), Killing after three weeks.

Group V: (Injection PSNPs), Killing after four weeks.

End of the experiment, mices were killed for study Histological, sections.

\subsubsection{Histological, Sections, Preparation}

The tissues (lung, spleen, and skin) were collected from mice in the control and PSNP-treated groups. These organs were preserved in 10\% formalin [21], and their slices were performed in the central lab. Baghdad Hospital- Iraq.

\subsection{Statistical Analysis}

A p-value of $<0.05$ was considered significant. Unpaired $t$ test using comparison between groups was made [15].

\section{Results and Discussion}

\subsection{UV-Vis Spectroscopy}

Figure (1) depicts the colors of PSNPs colloidal NPs used to reduce the size of silicon nanoparticles in double deionized water at various NP concentrations of $(750,500$, and 250$) \mathrm{g} / \mathrm{ml}$. The degree of color relies on the concentration of PSNPs and increasing the concentration of NPs and the number of laser pulses will increase particle concentration. From light orange to dark gray, the color NPs are ordered. These are dependent on the NPs' form and size, as well as D.W.'s dielectric constant [22]. UV-Vis. is the measurement of the absorption of PSNPs within the wavelength range of 200-1000 nm. UV-Vis. for PSNPs indicated that the top peak could be seen at 420 $\mathrm{nm}$, In Figure (2) curves 1, 2, and 3 at concerns. (750, 500 and 250) $\mu \mathrm{g} / \mathrm{ml}$ respectively with absorption intensities of $(0.98,0.70$, and 0.35$)$ the wavelength $(448) \mathrm{nm}$ has the maximum absorption intensity. As a result, we may deduce that the concen. rose as absorbance increased. PSNPs have a high absorption factor at short wavelengths, as seen in the graph. This suggests that the optical absorption is caused by a direct spectral transition [23]. 


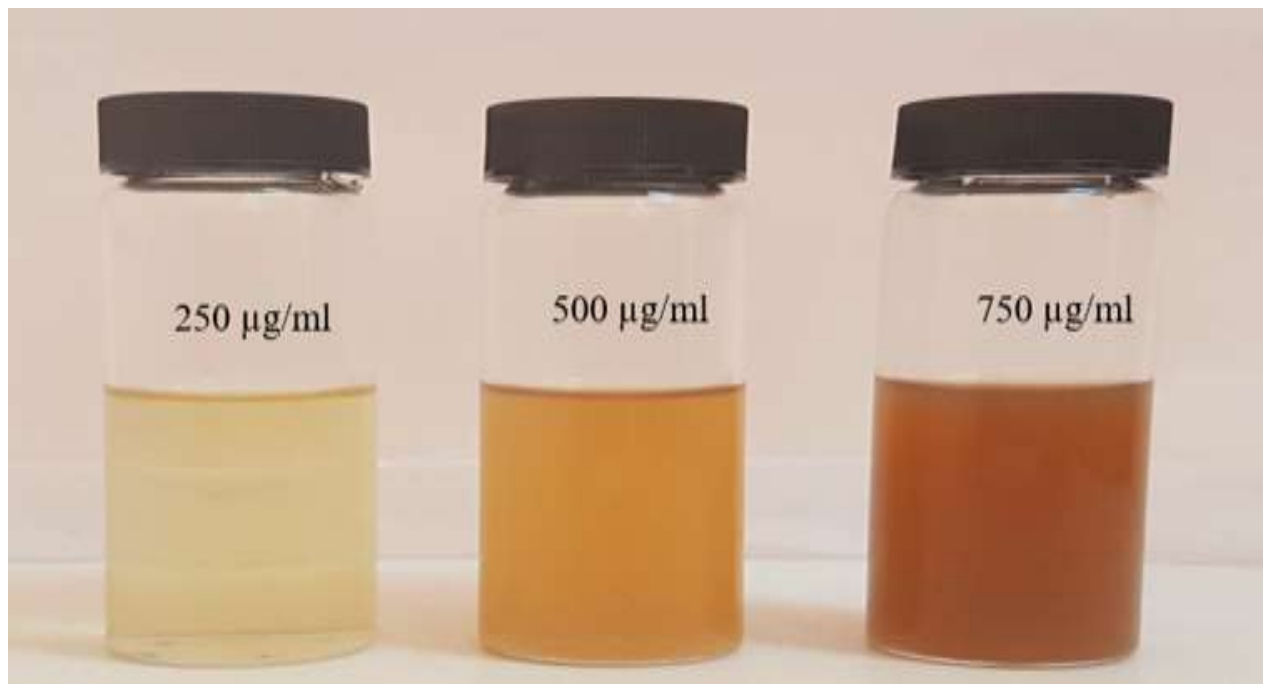

Figure 1: PSNPs colloidal by using high-power laser.

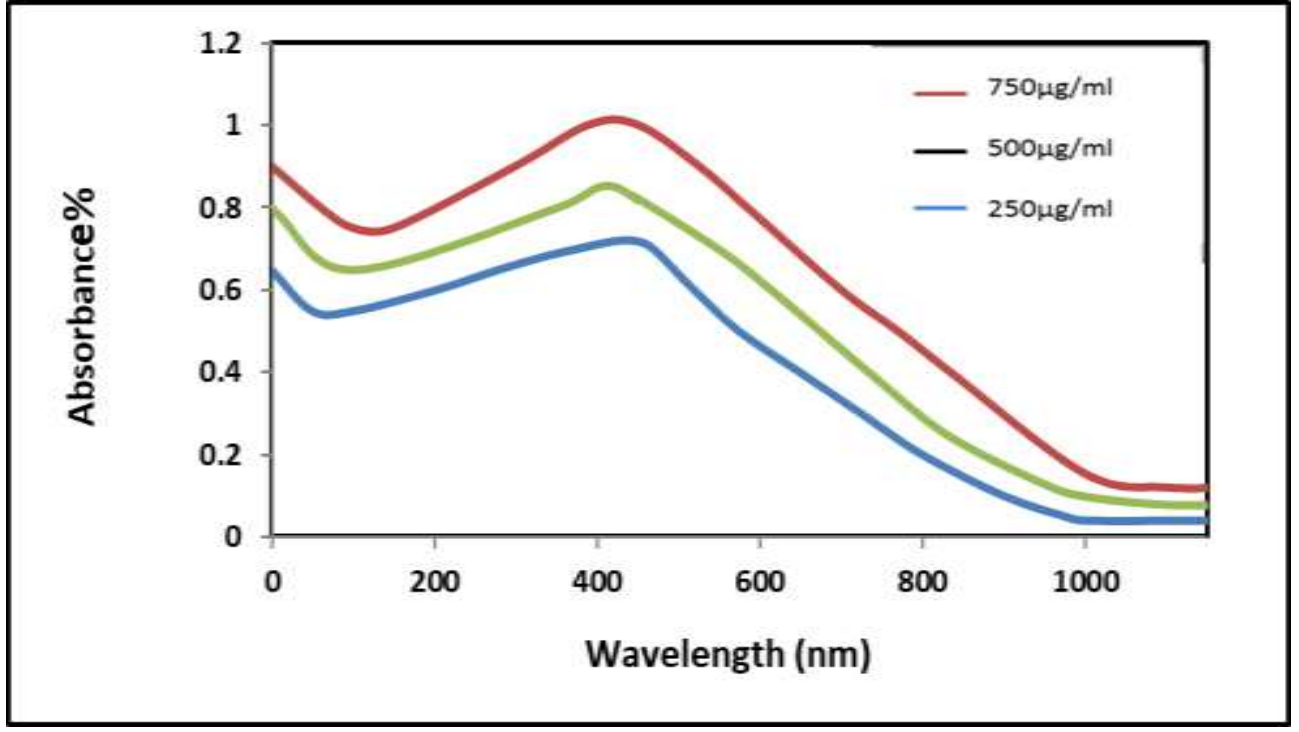

Figure 2: UV-Vis spectroscopy of PSNPs.

\subsection{X-Ray Diffraction XRD Analysis}

Figure (3) demonstrates an increase in peak intensity with increasing concentration at $750 \mathrm{~g} / \mathrm{ml}$. In Table, there is also less displacement at the diffraction angle (4.3). This implies that the PSNPs of the FCC type have levels (111) and (100) of $2=28.5$ and 70, respectively. At a concentration of $500 \mathrm{~g} / \mathrm{ml}$, the porous structure causes reduced breading and intensity, as well as a decrease in size, resulting in breading of the plan (111) and (100) at 2=28.5 and 70, respectively. A broadening of the diffraction peak was found at concentration $250 \mathrm{~g} / \mathrm{ml}$, with the broader of the peak suggesting a drop in nanosize, and at 2=28.5 and 70 with the levels (111) and (100) showing a decrease in particle size than the other concentrations. 


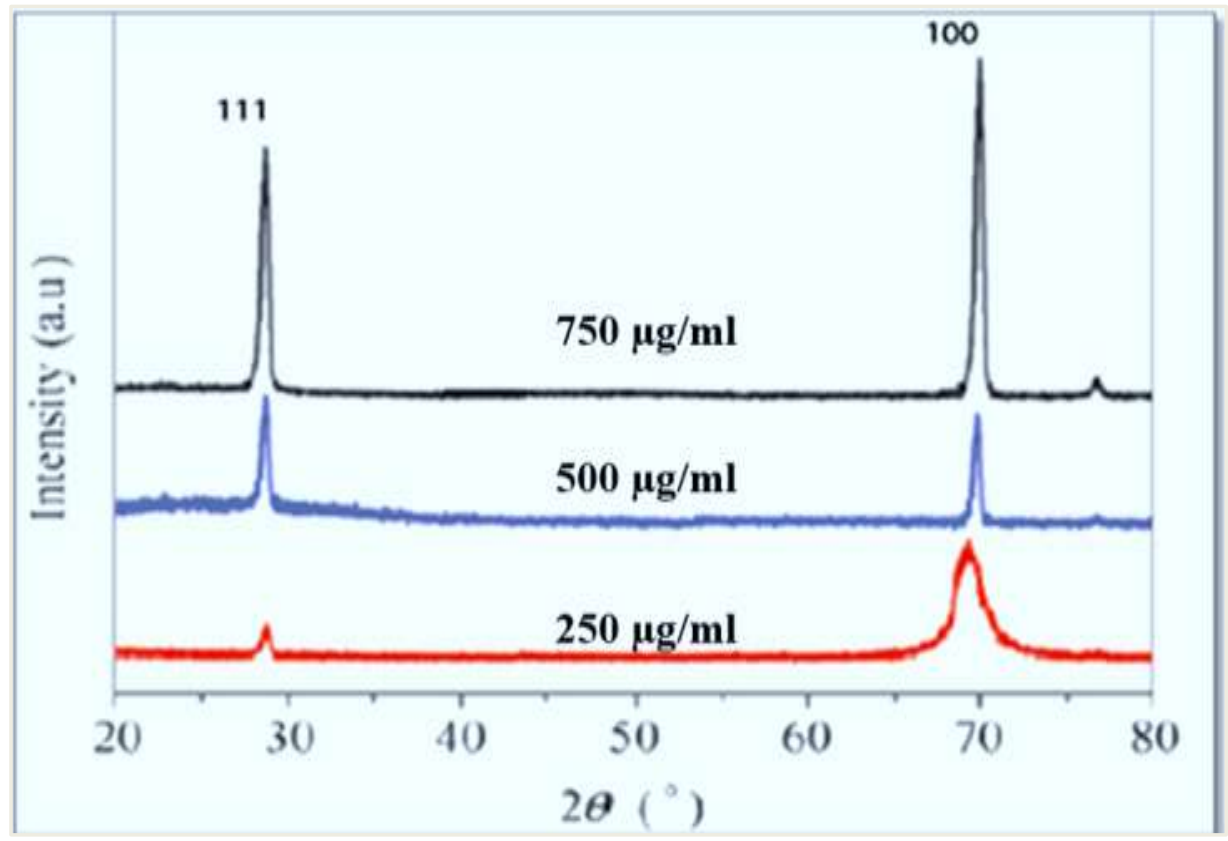

Figure 3: XRD of PSNPs

\subsection{SEM}

Figure (4) shows the SEM findings of the PSNPs, with particle sizes of 35.5, 65, and $75 \mathrm{~nm}$, respectively. These results suggest that the increase in concentration was accompanied by an increase in nanosize. At a concentration of $250 \mathrm{~g} / \mathrm{ml}$, the typical particle size is $18-70 \mathrm{~nm}$. At concen. $500 \mathrm{~g} / \mathrm{ml}$, the average particle size is (35-70) $\mathrm{nm}$, and the particle rate is $10-160 \mathrm{~nm}$, whereas at concen. $750 \mathrm{~g} / \mathrm{ml}$, the average particle size is $35-70 \mathrm{~nm}$ and the particle rate is $10-160 \mathrm{~nm}$. Image J. software was used to evaluate the size of the NPS, which is dependent on the concen. Value, with the higher the concen. the greater the NPS size.
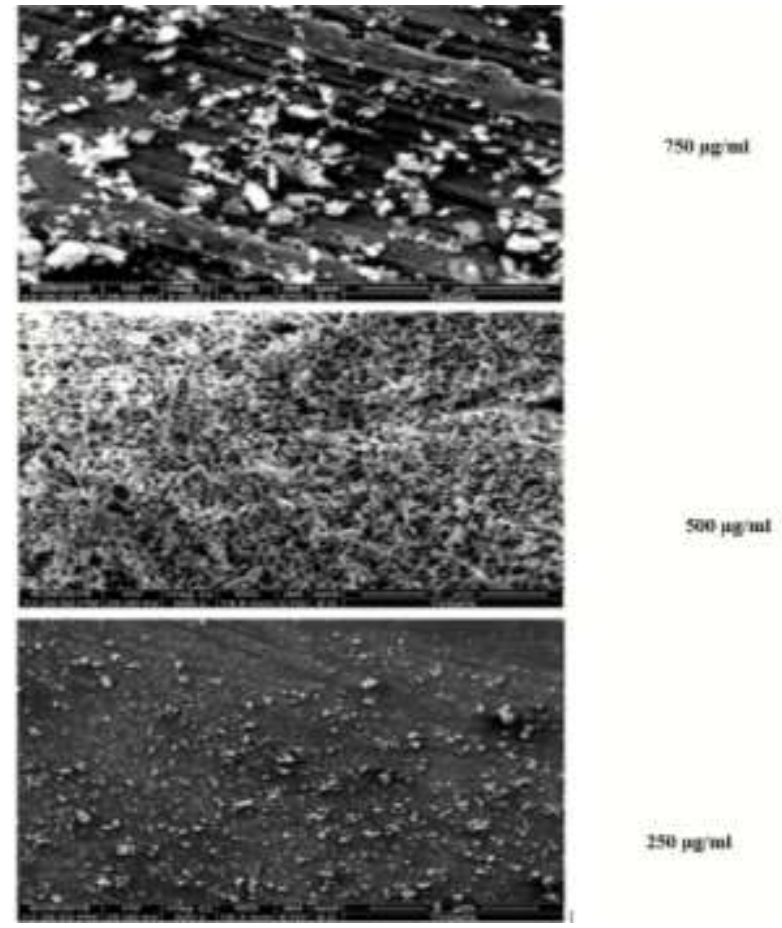

Figure 4: SEM of the PSNPs 


\subsection{Antioxidant Action of PSNPs}

The DPPH was shifted exactly proportionate to the rise in concentration, according to the results of my research. When antioxidant chemicals returned a proton and an electron, the hue shifted to yellow [16]. Concern. of $(25,50$, and 75$) \mathrm{g} / \mathrm{ml}$ is provided to free radicals at $(42.56,50.94$, and 57.22) respectively, as compared to control positive, as shown in figure (5). The high concentration of PSNPs of Si-O-Si might be to blame for the increase in displaced free radicals. The findings revealed that the high content $\mathrm{SiO}$ stretching in $(\mathrm{O}-\mathrm{SiO}), \mathrm{CH} 3$ symmetric stretching, $\mathrm{CO}$ binding, $\mathrm{CH} 2$ symmetric stretching, and $\mathrm{OH}$ stretching $(\mathrm{SiOH})$ are all responsible for antioxidant action [24, 25, 26, 27, 31]. Enzymatic antioxidants have a role in cellular defense against ROS [28], and they have been hypothesized to serve as antioxidants.

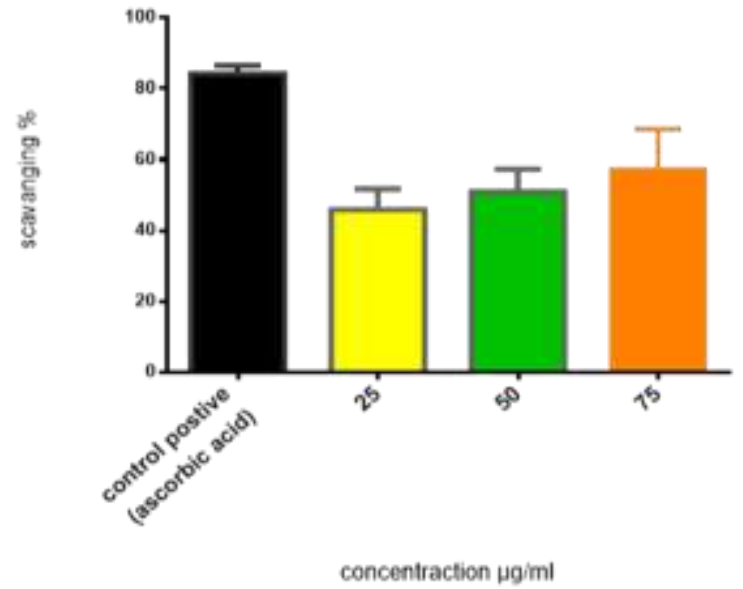

Figure 5: Scavenging activity of PSNPs.

\subsection{Anticancer action of PSNPs}

PSNPs' impact on tumor cell proliferation for 48 hours, Hella cells were treated with various doses of PSNPs (25, $50,75 \mathrm{~g} / \mathrm{ml})$. The cytotoxicity test resulted in a statistically significant impact. The concerns. of $(75,50$, and 25$)$ $\mu \mathrm{g} / \mathrm{ml}$ had a greater impact than the concentration of $25 \mathrm{~g} / \mathrm{ml}$, indicating that PSNPs can suppress cancer cell proliferation (Figure 1). (6). PS NPs with a size of $39 \mathrm{~nm}$, on the other hand, demonstrate anticancer activity against kidney tumors at a concentration of (400) $\mathrm{g} / \mathrm{ml} \mathrm{[31].}$

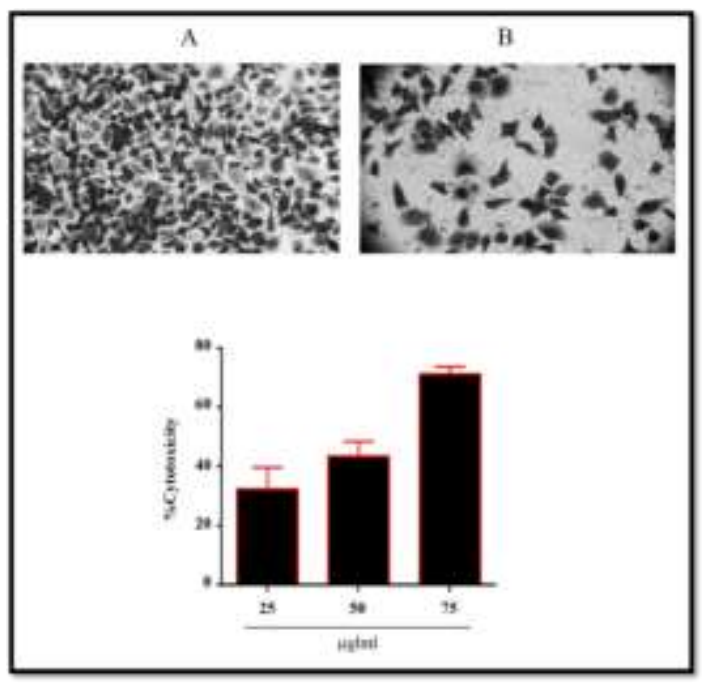

Figure 6: Effect of PSNPs in growth of HeLA cells. 


\subsection{Evolution the Effect of PSNPs in Vivo}

To study the effect of PSNPs in tissues and body weight.

\subsubsection{Measurement of Body Weight}

The body weight findings, as shown in Figure 7, revealed no significant changes in body weight between the treatment groups

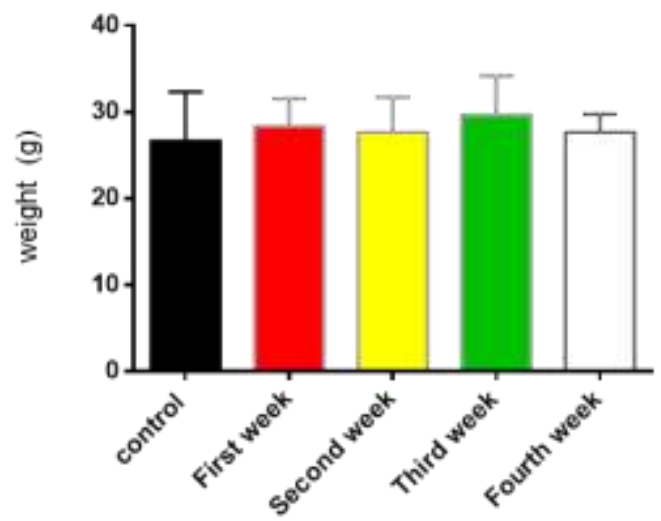

Figure 7: Result of PSNPs on body weight of mice.

\subsubsection{Evolution Histopathology of PSNPs}

PSNPs were injected into the lung, spleen, and skin of mice for four weeks to determine their impact. There are no changes in histology results between the treatment and control groups. figures (8,9 and 10). As indicated in figure 8 , there was no change in the surface of the red pulp or the size of the lymphoid follicles in the spleen. Figure 9 depicts the typical anatomy of the lung, including alveoli and alveolar space, as well as the existence of bronchials. In figure 10, skin tissue depicts the typical structure of the skin. 


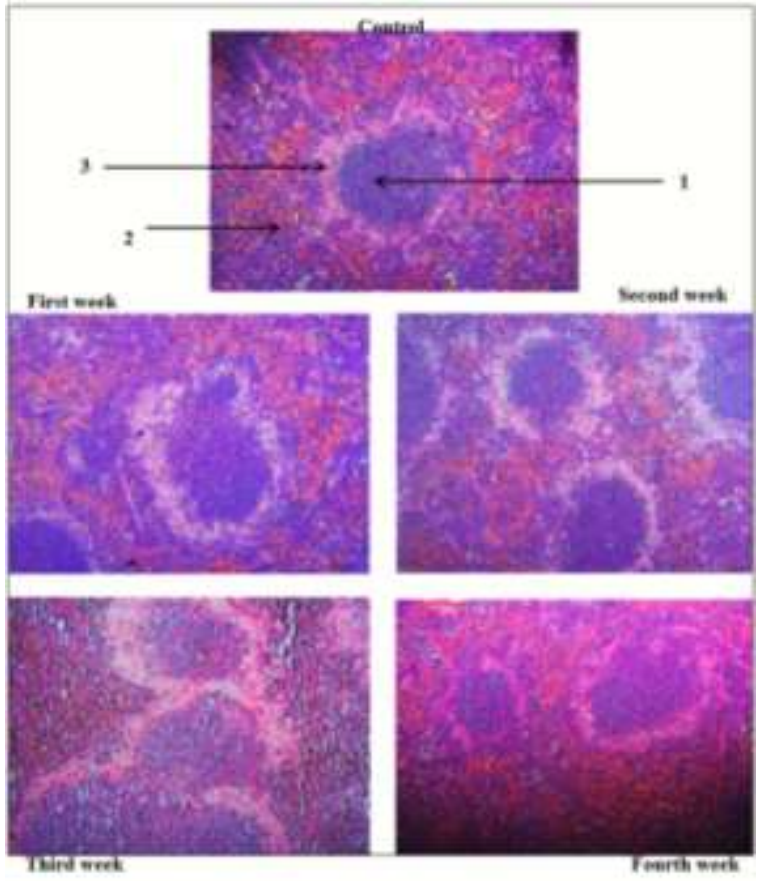

Figure 8: Image spleen tissue treated with PSNPs $1 \mathrm{mg} / \mathrm{kg}$. [1-Germenal center of a spleen follicle.2-Splenic red pulp.3-Corona]. (H \& E.100x).

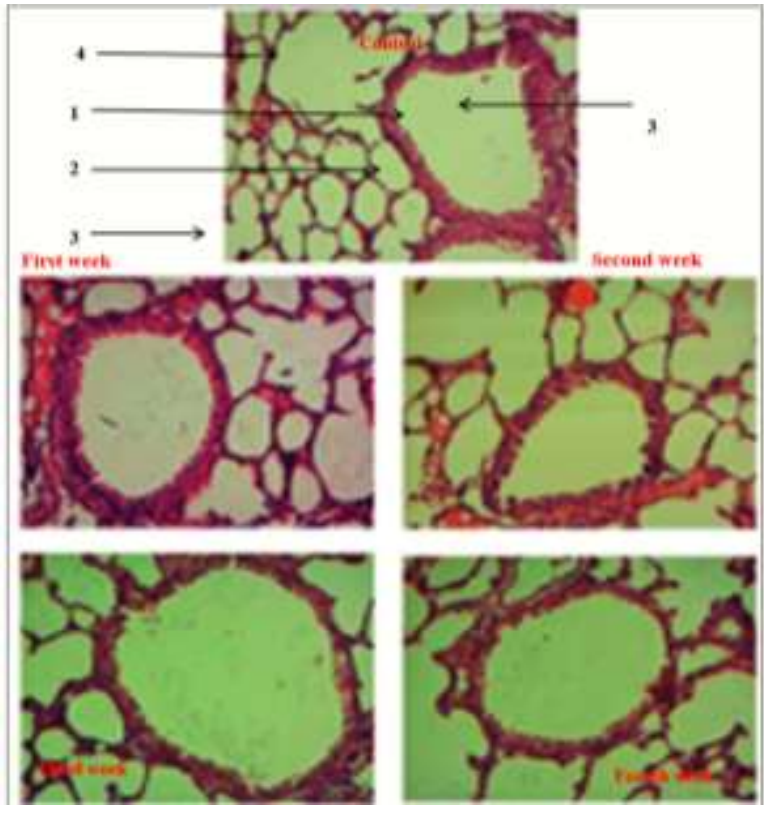

Figure 9: Image in lung tissue treated with PSNPs $1 \mathrm{mg} / \mathrm{kg}$ [1-Bronchus with folded mucosa.2-Tunica muscularis.3-Alveoli.4-Alveolar ducts]. (H \& E.100x). 


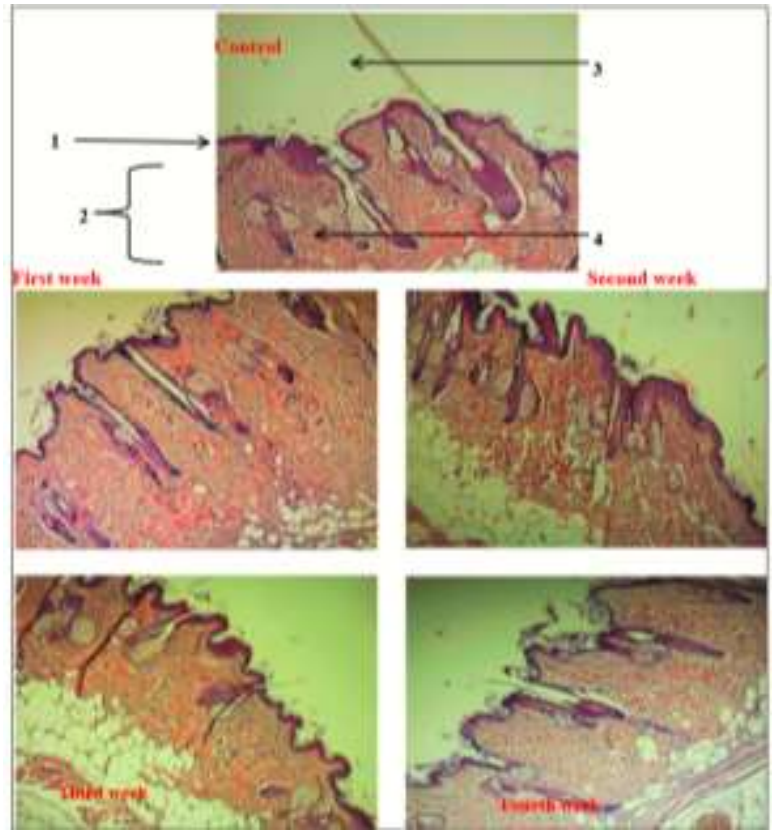

Figure 10: Image in skin tissue treated with PSNPs (1mg/kg). [1-Epidermis.2-Dermis.3-Hair shaft.4-Oil gland]. (H \& E.100x).

Biocompatibility and biodegradability of PSNPs in vivo were examined. The PSNPs preparation is relatively nontoxic in vivo within the examination concentration range. This result compared with the slow removed normally observed for other kinds of inorganic nanoparticle [29]. By terminating a period of 4 weeks. In vivo studies, PSNPs $(1 \mu \mathrm{g} / \mathrm{kg})$ were injected intraperitoneal into mice. However, the PS NPs collected in the organs are noticeably removed from the body within a period of first week and totally removed in four weeks. The mice of porous silicon nanoparticle internalization have been shown to be determined by particle size [30]. Some factors are thought to have a profound effect on the development of mediated toxicity nanoparticle. The key factor is nanoparticle diameter, which, at minimum for colloidal nanoparticle, inversely associated with the surface area. Special toxicological effects of PSNPs in mice were more established by histopathological investigation. Figure $(8,9,10)$ shows that no atypical in histopathological findings were shown in lung, spleen, skin after 4-week injection of PSNPs. This result clearly shows that PSNPs did not cause toxic effects. Pathological damage associated to the test materials was not shown in every treated group. Porous silicon nanoparticle used in the present study did no source severe toxicity in mice. On contrast study, the results indicate that the PS NPs had not cause toxic effects at all examined [31].

\section{Conclusions}

PS reasonably biocompatible nanomaterials. Toxicity of PSNPs was assessed in mice and in vivo after 4-weeks. Results injection that PSNPs did not because cytotoxic effects after 4- weeks, with added PSNP have potential antioxidant and anticancer activity.

Acknowledgement: The authors thank the of University of Technology- Iraq for funding the activities presented in this study.

Conflict of Interest: There are no conflicts of interest declared by the authors. 


\section{References}

[1] M. P. Stewart and J. Buriak, "Chemical and biological applications of porous silicon technology," Advanced Materials, vol.12, no. 12, p 859-869, 2000.

[2] J.Hernández-Montelongo, A.Muñoz-Noval, V.Torres-Costa, R.Martín-Palma, et al., "Cyclic Calcium Phosphate Electrodeposition on Porous Silicon". International Journal Electronic Chemical Sciences.vol.7, p.1840-1851, 2012.

[3] EJ.Anglin, L.Cheng, WR.Freeman, MJ. Sailor, et al., "Porous silicon in drug delivery devices and materials". Advanced Drug Delivery Review, vol.60, no.11, p.1266-1277, 2008.

[4] DM.Reffitt, R. Jugdaohsingh, RP. Thompson, JJ.Powell, et al., "Silicic acid: its gastrointestinal uptake and urinary excretion in man and effects on aluminum excretion," Journal Inorngic Biochemical,vol.76, no. 2, p.141-147, 1999.

[5] R. Hérino, "Nanocomposite materials from porous silicon," Mathematics Sciences Engineering, vol.69, p.7076, 2000.

[6] R E. Fernandez, S. Stolyarova, A. Chadha, E. Bhattacharya, Y. Nemirovsky et al., "MEMS composite porous silicon/polysilicon cantilever sensor for enhanced triglycerides biosensing," IEEE Sensors Journal, vol.9, no.12, p.1660-1666, 2009.

[7] K. L. Jarvis, T. J. Barnes, and C. A. Prestidge, "Surface chemistry of porous silicon and implications for drug encapsulation and delivery applications". Advanced Colloid Interferences Sciences, vol.175, p.25-38, 2012.

[8] S. P. Low, N. H. Voelcker, L. T. Canham, K. A. Williams," The biocompatibility of porous silicon in tissues of the eye," Biomaterials, vol.30, p.2873-2880, 2009.

[9] V.Parkhutik, "Analysis of publications on porous silicon: from photoluminescence to biology, "Journal Porous mathematic,vol.7, no.1, p.363-366, 2000.

[10] LT.Canham, T.Cox, A.Loni,A. Simons, et al.," Progress towards silicon optoelectronics using porous silicon technology," Applied Surfaces Sciences, vol.102, p.436-441, 1996.

[11] L. Pavesi , and P. Dubos, "Random porous silicon multilayers: application to distributed Bragg reflectors and interferential Fabry-Perot filters," Semiconductors Sciences Technology, vol.12, no.5, p.570-575, 1997.

[12] P.Menna, G.Di Francia, and V.La Ferrara, "Porous silicon in solar cells: a review and a description of its application as an AR coating," Solar Energy Mater Solar Cells, vol.37, no.1, p.13-24, 1995.

[13] M. Lee, Y. Wang, and C. Chu, "High-sensitivity porous silicon photodetectors fabricated through rapid thermal oxidation and rapid thermal annealing," IEEE Journal Quantum Electron, vol.33, no.12, p. 2199-2202, 1997.

[14] A. Loni, L. Canham, M. Berger, R. Arens-Fischer, H.Munder, Luth H, et al., "Porous silicon multilayer optical waveguides," Thin Solid Films, vol. 276, no.1, p.143-146, 1996.

[15] M. Jabir, U.Nayef, K.H.Jawad, et al.," porous silicon nanoparticles prepared via an improved method: a developing strategy for a successful antimicrobial agent against Escherichia coli and Staphylococcus aureus". IOP Conference Series: Materials Science and Engineering, vol. 454, p.012077, 2018.

[16] K.J. Hussein, "Effects of Ag nanoparticles prepared by Nd-YAG lasers and study their antibacterial and antioxidant activity," Plant Archives, vol. 20, no.1, p. 3481-3486, 2020.

[17] K. H. Jawad, B. A. Hasoon, and N. Hussein," Biological application of titanium dioxide nanoparticles prepared through laser ablation in liquid,"Drug Invention Today, vol.12, no.12, 2019.

[18] K. H. Jawad,"Preparation and characterization of silicon nanoparticles for bio medical applications". Ph.D. thesis, University of Technology, Baghdad, Iraq, 2017.

[19] K. H. Jawad, M. S. Jabir, and U. M Nayef, "A study of kidney Parameters Induced by Porous Silicon Nanoparticles,"Engineering and Technology Journal, vol. 35, no. 2, 2017.

[20] K. H. Jwaid, M. S. Jabir, and U. M. Nayef, "Toxicity of Porous Silicon Nanoparticles on Liver of Mice," AlMustansiriyah Journal of Science, vol. 28, no. 3, 2017.

[21] J.Bancroft, and G.Marilyn, G. ,"Theory and practice of histological techniques," 1st ed., Elsevier, 2008.

[22] S. Eustis, " Gold and Silver Nanoparticles: Characterization of their Interesting Optical Properties and the Mechanism of their Photochemical Formation," PhD thesis, Georgia Institute Technology., 2006.

[23] J.A.Luna-López , M. Aceves-Mijares, J.Carrillo-López, A. Morales-Sánchez., et al.,'UV-Vis Photodetector with Silicon Nanoparticles," Photosets, vol.51, p.978-953, 2012.

[24] T.F. Young and C.P. Chen, "Study on the Si-Si Vibrational States of the Near Surface Region of Porous Silicon,” Journal Mater Kluwer.no.7, p.339 -342, 2000. 
[25] M.A.Vasquez-a , G.Aguila Rodriguez, G. Garcia-Salgado, G. Romero-Paredes , and R.Pena-Sierra , "FTIR and photoluminescence stuidies of porous silicon layers oxidized in controlled water vapor conditions," ,Revwier,vol. 53, no.6, p,431-435, 2007.

[26] N. Jeyakumaran, B.Natarajan,S. Ramamurthy , and V.Vasu, "Structural and Optical Properties of n-Type Porous Silicon-Effect of Etching Time," International Journal Nanoscilicon Nanotechnology, 5, 2007.

[27] O. Bisi, S. Ossicini and L. Pavesi, "Porous Silicon a Quantum Sponge Structure of Silicon Based Optoelectronics," Surfaces Sciences, vol.38, p. 1-126, 2000.

[28] K. Taeho, B. B. Gary, S. Zhi-gang, H. Sazid, R. Erkki, and J. S. Michael, “Composite Porous Silicon-Silver Nanoparticles as Theranostic Antibacterial Agents," ACS. Applied Mater Interfaces, p.1-27, 2016.

[29] B. Ballou, B. C. Lagerholm, L. Ernst, M. P. Bruchez, and A. S. Waggoner, "Noninvasive imaging of quantum dots in mice," Bioconjugate Chemical, vol.15, p.79-86, 2004.

[30] N. H. Maniya, S. R. Patel, Z.P.Murthy, "Electrochemical preparation of microstructured porous silicon layers for drug delivery applications," Super lattices and Microstructures, vol .55, p.144-150, 2013.

[31] J. H. Park, L. Gu, G. Maltzahn, E. Ruoslahti, N. Sangeeta, and J. Michael, "Biodegradable luminescent porous silicon nanoparticles for in vivo applications," Nature materlals, vol. 8, p. 331-336, 2009. 